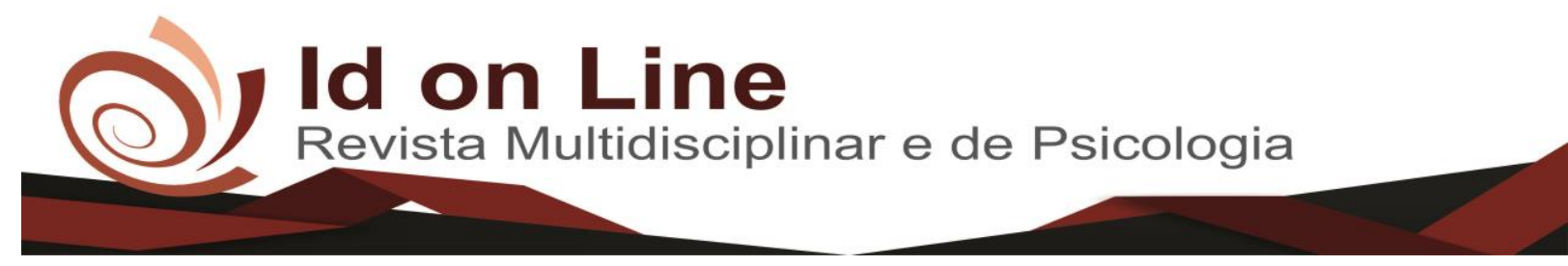

Artigo de Revisão

\title{
O Brincar e o Aprender na Educação Infantil
}

\author{
Eliza Naiane Rodrigues ${ }^{1}$; Maria do Socorro Januário Alves ${ }^{2}$; Maria do Socorro Cecílio Sobral ${ }^{3}$
}

\begin{abstract}
Resumo: Brincar é uma necessidade para o desenvolvimento da criança. Sendo assim, é o direito que ela tem, inclusive consta no Estatuto da Criança e do Adolescente, no Artigo n ${ }^{\circ} 16$. Muitos pensam que a criança brinca apenas para se distrair e por prazer, mas a brincadeira é uma grande necessidade, porque de acordo com a idade da criança, a brincadeira evolui e a própria relação da criança com o adulto se modifica. O presente artigo trata de uma pesquisa bibliográfica que busca identificar as bases teóricas que sustentam o brincar e o aprender no ensino aprendizagem de crianças na educação infantil, fundamentada na reflexão de leituras autores renomados como Andrade (2013), Antunes (2013), Ramos, (2012), Raul (2007), Rolim, (2014) e RCNEI (2001), os quais discutem com precisão a temática aqui abordada. O objetivo deste estudo é demonstrar de que forma o brincar contribui com o ensino aprendizagem nas crianças na educação infantil. Os dados foram obtidos por meio de análises de textos de dos quais nos dá embasamento da importância da prática do brincar para a concretização do aprender. É preciso repensar em uma prática pedagógica que privilegie as brincadeiras na formação integral da criança.
\end{abstract}

Palavras-chave: Aprendizagem, Brincadeira, Criança.

\section{The Playing and Learning in Early Childhood Education}

\begin{abstract}
Play is a necessity for the development of the child. Therefore, it is the right that she has, including the Statute of the child and adolescent, in article 16. Many think that the child plays just to distract you and take pleasure, but the joke is a great need, because according to the child's age, the game evolves and the relationship of the child with the adult changes. This article discusses a bibliographical research that seeks to identify the theoretical bases supporting the play and learning in teaching learning in early childhood education, grounded in reflection of renowned authors reads like Andrade (2013), Antunes ( 2013), Ramos, (2012), Raul (2007), Rashidi, (2014) and RCNEI (2001), in which they discuss the theme here addressed. The aim of this study is to demonstrate how play contributes to the teaching learning in children of early childhood education.The data were obtained through analyses of texts of which gives us support of the importance of play in the implementation of learning. We need to rethink in a pedagogical practice that focuses on the games in the integral formation of the child process.
\end{abstract}

Keywords: Learning. Childhood. Child.

\section{Introdução}

O brincar para a criança é um processo de mediação entre ela e a realidade. A brincadeira é de primordial importância a saúde física, emocional e intelectual, por isso o brincar está

\footnotetext{
${ }^{1}$ Faculdade de Ciências Humanas do Sertão Central (FACHUSC). elizanaianerodrigues@ hotmail.com;

${ }^{2}$ Faculdade de Ciências Humanas do Sertão Central (FACHUSC). socorroalvesjanuario@ hotmail.com;

${ }^{3}$ Faculdade de Ciências Humanas do Sertão Central (FACHUSC). socorrosobral@bol.com.br;
} 
presente em todos os momentos da vida de uma criança. Pela brincadeira a criança desenvolve seus sentidos, alcançam inúmeras habilidades identificar objetos e suas características como formas, texturas, tamanhos, cores e sons.

$\mathrm{Na}$ brincadeira, a criança entra em contato com o ambiente, obtêm meios para relacionar-se com os demais, elevar a autoestima, a afetividade e se torna em um ser ativo, curioso, descobridor de tudo o que o cerca, sociável e cheio de cultura.

Assim, com a proposição deste estudo, almeja-se de forma específica: abordar o ato de brincar na fase infantil, indicando-o como sendo papel essencial no desenvolvimento biopsicossocial da criança; o lúdico como recurso essencial à aprendizagem, destacando a importância da vivência lúdica das crianças na Educação Infantil e os desafios a se percorrer; As brincadeiras como recurso estimulador do aprendizado, ressaltando a prática do uso dos brinquedos, das brincadeiras e os jogos no ensino da educação infantil como recursos essenciais ao desenvolvimento físico, mental e socioemocional das crianças; o professor da educação infantil como agente motivador da aprendizagem.

De acordo com os Parâmetros Curriculares Nacionais, (1998, P.21) a educação infantil, a criança é um sujeito social e histórico e faz parte de uma organização familiar que está incluído em uma sociedade, com determinada cultura, em determinado momento histórico. É profundamente marcada pelo meio social em que se desenvolve. Por isso precisa ser um lugar agradável, formado de valores voltados para aprendê-lo a ser.

O desenvolvimento psíquico- social de uma criança se dá quando a ela é oferecida condições para tal. Impossível querer que uma criança se desenvolva se a ela não for oferecida recursos que de fato possa fazer isto acontecer. Para a criança desenvolver suas múltiplas aprendizagens é necessário dispor de recursos facilitadores que o leve a isso. Assim, destaca-se o lúdico como fator essencial para tal atividade. O lúdico favorece a autoestima novas experiências afetivas, sociais, motoras e cognitivas quando se dá dentro de um ambiente educacional agradável.

A criança que brinca é mais esperta, mais interessada, aprende mais fácil. O brincar favorece a criança os laços afetivos e eleva o nível de interesse dela com a brincadeira, estimula a sua imaginação e o seu aprendizado.

O lúdico é uma prática de treinamento de habilidades psicomotoras, meio pelo qual se concretiza aprendizado. Dessa forma, a ludicidade tem que ser entendido como meio essencial à prática pedagógica e por isso deve estar pautada nos planos de ensino do educador, com atividades direcionadas ao brincar, uma vez que esta representa a essência de formação, do aprendizado das crianças. 


\section{$O$ ato de brincar no ensino infantil}

É durante a infância que se dar as interações entre o mundo e o meio em que a criança vive e consequentemente uma aprendizagem significativa. É impossível ver a infância como etapa das brincadeiras, do lúdico, sem pensar no brincar. É nessa etapa que brinquedos e brincadeiras se entrelaçam. Ao lembrar de criança e infância, automaticamente lembra-se de educação infantil.

Durante muito tempo a brincadeira era vista pela sociedade como uma negação ao trabalho e desinteresse pelo sério. Porém os estudos contemporâneos se preocupam cada vez mais em observar a infância e as suas brincadeiras, buscando compreender as formas de sociabilidade da criança e seu diálogo com a cultura adulta.

O processo de preparação para a fase adulta até então entendido, passou a centralizar-se nas práticas da criança e suas experiências de autonomia. O que se entende é que a brincadeira é e sempre será uma das linguagens que se destacam na infância com significação e ressignificação do mundo constituindo suas práticas culturais.

A brincadeira é a ação mais marcante na vida da criança e a forma prazerosa para ela movimentar-se e ser um ser independente. Pelo o ato de brincar, a criança desenvolve seus sentidos, alcança inúmeras habilidades para poder usar mãos e corpo, identifica objetos e suas características, suas texturas as formas, os tamanhos, as cores e os sons.

$\mathrm{O}$ ato de brincar tem um papel essencial no desenvolvimento biopsicossocial da criança. É nesse momento que ela se observa, explora característica de personalidade, fantasias, medos, desejos, criatividade e elabora o mundo exterior a partir de seu campo de visão. Brincando a criança entra em contato com o ambiente, aufere meios para melhor relacionar-se com os demais, alegrar-se, elevar a autoestima, ser mais afetiva e sociável e tornar-se assim um ser ativo, curioso e formador das suas próprias descobertas e aprendizagens. No brincar, a criança constrói e recria um mundo onde seu espaço esteja garantido.

O Referencial Curricular Nacional Para Educação Infantil (2001) afirma que a criança é profundamente marcada pelo meio social em que se desenvolve, mas também o marca. A criança tem na família, biólogo ou não, um ponto de referência fundamental, apesar da multiplicidade de interações sociais que estabelece outras instituições sociais. 
Assim sendo, contata-se que o meio social é de primordial importância na formação das crianças seja ele biólogo ou não, devem propor a esses pequenos seres total segurança, confiança, afeto, respeito se pretendem de fato vê-las no futuro seres amáveis e sociáveis.

\section{O lúdico como recurso essencial à aprendizagem}

O lúdico é um recurso favorecedor da autoestima da criança e da interação deles com as

outras. É também o meio pelo qual se concretiza o desenvolvimento das capacidades cognitivas.

A ludicidade quando colocada no contexto da sala de aula, possibilita a criança momentos agradáveis, capacidades de criar e imaginar, desenvolver-se e aprender com maior facilidade, pois ao praticar uma atividade lúdica, a criança desenvolve-se por completo.

A psicopedagogia tem a proposta de perceber o sujeito da aprendizagem como ator de um processo o qual considera tudo o que está a sua volta. Ou seja, que a criança ao chegar à escola, traz consigo toda uma pré-história da qual é construída pelas vivências lúdicas encontradas ao seu meio.

Por meio do lúdico a criança é capaz de relacionar o que se encontra ao seu meio com o social, transpondo a emoção do seu imaginário. Nestas transposições é possível dá-se a curiosidade, o conhecimento, as representações, as superações, o desenvolvimento afetivo e cognitivo. Pelo lúdico as crianças conseguem promover de forma significativa, novas experiências afetivas, sociais, motora e cognitiva, dentro de um ambiente educacional agradável e prazeroso.

Através das atividades lúdicas, as crianças, desenvolvem o senso de organização, o espírito crítico e competitivo, o respeito mútuo, além de aprenderem com muito mais facilidade.

O lúdico tem um papel muito mais amplo e complexo do que, simplesmente, servir para treinamento de habilidades psicomotoras, muitas vezes, assim colocadas. Através das vivências lúdicas, o aprendizado se dá de forma mais completa. A criança adquire posse de si mesma e do mundo de um modo criativo e pessoal.

Ressalta-se, portanto que utilizar atividades lúdicas (brincadeira, jogo, desenho, dança) não nos dá a certeza de que necessariamente esteja sendo vivenciada uma atividade lúdica plena, de integração do sentir, pensar e agir.

Para a realização de uma atividade lúdica é necessário que o seu objetivo esteja voltado para uma vivência prazerosa, onde o seu desenvolvimento seja totalmente saudável. 
Assim, é de primordial importância a vivência lúdica das crianças na Educação Infantil. É uma necessidade para as crianças e se constitui em grande desafio para nós, educadores e educadoras, que lidamos, principalmente, com crianças em fase inicial de aprendizagem. Porém, não se pode esquecer de que para uma brincadeira ser lúdica é preciso que esta desenvolva na criança a vivência plena e entrega total na sua efetivação. Pois nem toda brincadeira é lúdica, nem toda atividade lúdica é uma brincadeira.

\title{
A brincadeira: Recurso estimulador do aprendizado
}

O brincar e o aprender são concepções que estão interligadas ao aprendizado da criança. Estes contribuem de forma significativa o aprimoramento nas diferentes áreas cognitiva, afetiva, social e psicomotora.

A brincadeira ocupa um lugar muito especial na vida das crianças. Por ela a criança desenvolve as mais variadas habilidades necessárias ao seu desenvolvimento de vida.

As atividades lúdicas são procedimentos educacionais que dão possibilidade à criança vivenciar sua própria descoberta, testar seu limite, aprender regras fundamentais de convivência e, sobretudo, desenvolver sua capacidade emocional e cognitiva. A respeito do brincar e aprender, segue-se concepção de estudiosos:

\begin{abstract}
O brincar relaciona-se ainda com a aprendizagem. Brincar é aprender; na brincadeira, reside a base daquilo que, mais tarde, permitirá à criança aprendizagens mais elaboradas. O lúdico torna-se, assim, uma proposta educacional para o enfrentamento das dificuldades no processo ensino-aprendizagem.(VYGOTSKY apud ROLIM,GUERRA e TASSIGNY, 2008,p.177 ).
\end{abstract}

Alguns estudiosos sustentam a utilização de jogos e atividades lúdicas como mecanismo facilitador do processo ensino aprendizagem. O trabalho na sala de aula pela prática do lúdico se concorre na interação entre aluno e professor. Almeida (apud RAU 2007, p.56) afirma que:

\footnotetext{
O processo de construção do saber através dos jogos e das brincadeiras se dá quando a criança ao participar de uma ação lúdica, estabelece metas, constrói estratégias, planeja e utiliza seu raciocínio e seu pensamento de forma "organizada", elaborando assim a sua aprendizagem.
}

Assim sendo, o uso desses recursos quando utilizados pelo professor com o intuito de ensinar, de mediar à aprendizagem, pode ser entendido como atividades pedagógicas facilitadoras de inúmeras aprendizagens significativas e prazerosas. 
O processo ensino aprendizagem dado pela ludicidade, precisa estar centrado nas habilidades as quais se deseja desenvolver nas crianças, com objetivos claros e precisos; que o professor conheça as necessidades de seus alunos e planeje de forma criativa, organizada e responsável atividade que atendam as necessidades educativas dos seus alunos. Pela prática do uso dos brinquedos, das brincadeiras e os jogos no ensino da educação infantil são constituídos recursos essenciais ao desenvolvimento físico, mental e sócio emocional das crianças. Esses recursos devem estar presentes em nas atividades desenvolvidas no ambiente escolar. Devem estar pautados nos planos de ensino com atividades direcionadas ao brincar, uma vez que esta representa para a criança, a essência de sua formação.

\section{O professor da educação infantil como agente motivador da aprendizagem.}

O papel do professor é primordial dentro da escola e se reflete em toda a sociedade, uma vez que é um agente ativo na formação dos cidadãos e um ser influenciador e motivador dos

seus alunos. É também o responsável pelo desenvolvimento das capacidades: memória, raciocínio e bem estar num ambiente repleto de pluralidade.

O educador da educação infantil é sem dúvida o verdadeiro pilar para educação das crianças pequenas. Por isto deve ser um ser motivado para fazer a diferença no aprendizado de cada ser que ali se encontra.

Desse modo, deve promover às crianças atitudes, estratégias e comportamentos favorecedores de melhor aceitação e desenvolvimento, de forma carinhosa e cheia de exemplo, que consequentemente levarão para fora do ambiente escolar. Esses comportamentos ajudarão certamente a construírem sua própria identidade, baseada na exploração de tudo que o rodeia, e assim vai compondo melhor seus relacionamentos interpessoais pelo uso dos conhecimentos e valores a si ensinados. Não se pode deixar de ressaltar as brincadeiras e os jogos como meios mais favoráveis e produtivos para este ato.

O professor desmotivado jamais conseguirá desenvolver em uma criança a aprendizagem com facilidade, isto porque esta vontade tem que estar dentro da pessoa do educador. $\mathrm{O}$ fazer pedagógico de um professor motivado é diferenciado em sala de aula. Cheio de encantos, alegrias e vontade de aprender.

Entende-se, portanto que é necessária a prática constante de atividades motivadoras de aprendizagem como a brincadeira. O brincar é marca constante na vida de uma criança. A criança que brinca é mais esperta, mais interessada, aprende mais fácil. Brincar com a criança 
reforça os laços afetivos, eleva o nível de interesse com a brincadeira e estimula ainda mais a sua imaginação.

As brincadeiras que povoam o universo infantil são a maneiras pela quais as crianças expressam-se no mundo. É nelas que elas representam papel, criam personagens, exploram brinquedos, enfim, encontram sentido para a sua vida.

É necessário ter consciência de que o jogo em sala de aula é o meio pelo qual o aluno aprende brincando. Portanto, ao final da brincadeira o professor precisa oportunizar as crianças a interagir contando suas experiências, refletindo sobre o quanto foi significativo aquele brincar e por fim, avalie seu desempenho.

Dessa forma, é preciso que a brincadeira esteja presente no ambiente escolar. Que os seus planos de ensino, contemplem atividades direcionadas ao brincar, onde se der seu desenvolvimento, compartilhamento das brincadeiras, dos jogos, das histórias de instigação da curiosidade, motivando as crianças conhecer o mundo que o cerca com liberdade e limites.

Nessa perspectiva, o Referencial Curricular Nacional da Educação Infantil (1998) diz que

\footnotetext{
O professor é o mediador das crianças come os objetos de conhecimento, organizando e propiciando espaços e situações de aprendizagens que articulem os recursos e capacidades afetivas, emocionais, sociais e cognitivas de cada criança aos seus conhecimentos prévios e aos conteúdos referentes aos diferentes campos de conhecimento humano. $\mathrm{Na}$ instituição de educação infantil o professor constitui-se, portanto, no parceiro mais experiente, por excelência, cuja função é propiciar e garantir um ambiente rico, prazeroso, saudável e não discriminatório de experiências educativas e sociais variadas.(BRASIL,1998,p.30)
}

Educar significa acima de tudo desfrutar da inter-relação entre os sentimentos, os afetos e a construção do conhecimento. Um processo educativo onde a afetividade ganha destaque, pois a afetividade e a estabilidade emocional ajudam mais a compreender e modificar o raciocínio da criança e levá-la a se envolver com a aprendizagem. Quando é dada ênfase as metodologias alicerçadas as atividades lúdicas, o aprendizado acontece com maior encantamento e validade.

\section{Metodologia}

A metodologia aplicada buscou fornecer os instrumentos necessário para a realização de uma pesquisa qualitativa bibliográfica, fazendo uso de leitura e análises de textos dos autores renomados, Andrade (2013), Antunes (2013), Ramos, (2012), Raul (2007), Rolim, (2014) e 
RCNEI (2001), dos quais forneceram subsídios necessários a compreensão da importância do brincar e o do aprender no ensino aprendizagem na educação infantil, buscando auxiliar os educadores que atuam ou que venham atuar nesta modalidade de ensino visando a construção dos saberes necessários ao ato de educar para a vida em sociedade.

\section{Resultados e Discussão}

Através desse estudo compreendeu-se que o brincar é algo natural na vida da criança, é espontâneo e prazeroso, faz parte do seu cotidiano e está presente em diferentes tempos e lugares de acordo com o contexto histórico e social ao qual se encontra inserida. Com o poder da imaginação e criação as brincadeiras vão sendo recriadas, de forma que as de outros tempos possam estar presentes na vida, mesmo que de maneiras diferentes, mas baseadas na cultura e no espaço geográfico.

Com o desenvolvimento dessa pesquisa percebeu-se que é necessário saber que ao utilizar recursos lúdicos no processo de ensino e aprendizagem, o educador deve ter conhecimento das teorias que tratam a psicologia do desenvolvimento humano, já que ambas consideram o desenvolvimento humano como um processo natural e social. Não é considerável utilizá-los de forma aleatória, mas certo de que serão eficazes à produção do conhecimento.

A investigação indicou que o brincar é um processo permanente de descoberta. A criança que brinca é mais esperta, mais interessada, aprende mais fácil. Brincar com a criança reforça os laços afetivos e eleva o nível de interesse dela com a brincadeira, estimulando ainda mais a sua imaginação e o seu aprendizado.

Percebeu-se também que é através da brincadeira que a criança toma conhecimento da sua cultura, do seu ambiente social, aprende e desenvolve papéis. Brincando a criança constrói e reconstrói a realidade partindo do imaginário. Para Andrade (2013):

\footnotetext{
Brincar é, portanto, experiência a vida. É se divertir em todas as etapas que compõem este processo, inclusive no ato de errar, pois a possibilidade de errar é uma das melhores partes do ato de brincar, uma vez que essa se torna desafiadora, e é o desafio que move a brincadeira (ANDRADE 2013, p.19).
}

Entendeu-se, por meio estudo, que as brincadeiras e os jogos são atividades que precisam de mudanças na sala de aula, o que exige um ambiente novo, recriado. Sendo o professor um ser paciente e determinado ao propor atividades diferenciadas. 
É necessário ter consciência de que o jogo em sala de aula é o meio pelo qual o aluno aprende brincando. Portanto, ao final da brincadeira o professor precisa oportunizar as crianças a interagir contando suas experiências, refletindo sobre o quanto foi significativo aquele brincar e por fim, avalie seu desempenho.

\section{Considerações Finais}

As possibilidades de autoconhecimento transmitidas pelas brincadeiras, muito tem contribuído com a formação de crianças mais seguras, autoconfiantes e conscientes do seu potencial e das suas limitações.

O brincar e o aprender são ações que fazem parte da infância de qualquer criança. É impossível deixá-las de lado na Educação Infantil quando são priorizados o seu direito de infância e as suas necessidades e potencialidades. Não se pode ver a infância como etapa das brincadeiras, do lúdico, sem pensar no brincar. O brincar é a ação mais marcante na vida de uma criança.

Através do brincar a criança adquiri seu desenvolvimento intelectual, realiza interações entre ela e o meio, constrói e recria um mundo, garantindo assim seu espaço como lugar rodeado de significações.

As possibilidades de autoconhecimento transmitidas pelas brincadeiras, muito tem contribuído com a formação de crianças mais seguras, autoconfiantes e conscientes do seu potencial e das suas limitações.

A instituição de educação infantil não pode ver o lúdico como ação de descontração, mas como um instrumento pedagógico que tem o poder de melhorar a autoestima e aumentar os conhecimentos indispensáveis ao processo de desenvolvimento das crianças que ali se encontram.

Quando somos postos a realizar alguma coisa na nossa vida, é necessário que se tenha vontade em fazê-lo. Do contrário, nada acontece. O mesmo acontece com os alunos em sala de aula. Se falta a motivação, o aprendizado não flui, não acontece. Daí a necessidade do professor ser motivador, de usar os brinquedos e as brincadeiras na sua prática nos seus planos de aula para que assim possa atender as necessidades de aprendizagem dos seus alunos. Pela motivação o educador consegue despertar a atenção, a curiosidade, a vontade de aprender, de frequentar e participar das aulas com mais entusiasmo. 
Acredita-se que o trabalho com as crianças na escola quando dado pela prática das brincadeiras garante uma aprendizagem significativa e um ser ativo, crítico, participativo, conhecedor e transformador de mundo. Esses meios são sem dúvida um dos caminhos a se trilhar, na formação cidadã.

\section{Referências}

BRASIL, Referencial Curricular Nacional para EducaçãoInfantil/Ministério da Educação e do Desporto, Secretaria da Educação Fundamental. Brasília: MEC/SEF, 2001.

Referencial Curricular Nacional paraa Educação Infantil.Ministério da Educação e do Desporto, Secretaria de Educação Fundamental. Vol. II.Brasília: MEC 1998.

ANDRADE, S. S. O lúdico na vida e na escola: desafios metodológicos.Curitiba: Appris, 2013.

ANTUNES, Celso. Jogos para estimulação das múltiplas inteligências. 19 ed. Petrópolis, RJ: Vozes, 2013.

RAU, M. C. T. D. A ludicidade na educação: uma atitude pedagógica. Curitiba: Ibpex, 2007.

RAMOS, Maria da Conceição Aparecida L. Jogar e brincar: representando papéis, a criança constrói o próprio conhecimento e, consequentemente, sua própria personalidade. Disponível em: http://www.icpg.com.br/artigos/rev01-07.pdf. Acesso: 27 mai 2012.

ROLIM, Amanda A. M.; GUERRA, Siena S. F.; TASSIGNY, Mônica M. Uma leitura de Vygotsky sobre o brincar na aprendizagem e no desenvolvimento infantil. disponível em http://brincarbrincando.pbworks.com/f/brincar\%2B_vygotsky.pdf. Acessado em 18 mai.2014.

\section{Como citar este artigo (Formato ABNT):}

RODRIGUES, Eliza Naiane; ALVES, Maria do Socorro Januário; SOBRAL, Maria do Socorro Cecílio Sobral. O Brincar e o Aprender na Educação Infantil. Id on Line Rev.Mult. Psic., 2019, vol.13, n.43, p. 187-196. ISSN: 1981-1179.

Recebido: 13/11/2018;

Aceito: 19/11/2018 